\title{
Robotic assisted treatment of flank hernias: case series
}

\author{
Matteo Di Giuseppe ${ }^{1 \dagger}$, Francesco Mongelli ${ }^{2^{*+}}\left(\mathbb{D}\right.$, Maria Marcantonio ${ }^{1}$, Davide La Regina ${ }^{1}$ and Ramon Pini ${ }^{1}$
}

\begin{abstract}
Background: Flank hernias are uncommon, surgical treatment is challenging and the minimally-invasive approach not always feasible. The aim of this study was to report the safety and feasibility of the robotic-assisted repair.

Methods: The study was approved by the local ethic committee (2019-01132 CE3495). A retrospective search on a prospectively collected dataset including demographic and clinical records on robotic surgery at our institution was performed to identify patients treated for a flank hernia. Patients were followed-up 6 months.

Results: From January 2018 to December 2019, out of 190 patients who underwent robotic-assisted hernia surgery, seven with incisional flank hernia were included. Median age was 69.0 years (IQR 63.2-78.0), BMI was $27.3 \mathrm{~kg} / \mathrm{m}^{2}$ (IQR 25.8-32.3) and two patients were male (29\%). All patients were referred to surgery because of pain, whereas one of them described recurrent episodes of small bowel obstruction.

The median hernia defect measured $25 \mathrm{~mm}$ ((IQR 21-40), median mesh diameter was $10 \mathrm{~cm}$ (IQR 10-12.5) and median operative time was 137 min (IQR 133-174). No intraoperative complication occurred.

Postoperatively, one patient developed a pneumonia, which required antibiotics. Length of hospital stay was 4.0 days (IQR 3.0-7.7). Six months after surgery, neither recurrence nor chronic pain were recorded.

Conclusions: Robotics in abdominal wall hernia surgery remains a matter of debate, despite a growing interest from the surgical community. In our reported experience with flank hernias, we found the robotic-assisted approach to be safe and feasible for the treatment of this uncommon clinical entity.
\end{abstract}

Keywords: Robotic-assisted, Minimally invasive, Flank hernia, Abdominal wall, Mesh

\section{Background}

Flank hernias are uncommon clinical entities, located lateral to the rectal sheath in the area $3 \mathrm{~cm}$ above and below the umbilicus [1]. Most commonly, these are incisional hernias, whereas spontaneous, post-traumatic and congenital forms have been described [2-4]. The surgical treatment is challenging, as a proper mesh fixation and overlap are made demanding by the regional bone and neurovascular

\footnotetext{
* Correspondence: francesco.mongelli@mail.com

${ }^{\dagger}$ Matteo Di Giuseppe and Francesco Mongelli contributed equally to this work.

${ }^{2}$ Department of Surgery, Ospedale Regionale di Lugano, via Tesserete 46, 6900 Lugano, Switzerland

Full list of author information is available at the end of the article
}

structures, with consequent limitation in the safety and feasibility of the minimally invasive approach $[2,5-7]$.

In the literature, open repair of flank hernia has been described in many series. However, the retrospective nature of most studies and the overall sample exiguity limit the level of evidence [5]. The open approach has been shown to be effective, but postoperative complication rate and hospital stay remain an issue $[2,3,8-11]$. In our experience, the laparoscopic treatment of this kind of hernias is technically demanding and not always feasible, so that conversion to open surgery is often needed.

Robotic surgery has been applied to ventral hernia repair, though flank hernias are reported sporadically and a strong evidence is far to be found [12-14].

(c) The Author(s). 2020 Open Access This article is licensed under a Creative Commons Attribution 4.0 International License, which permits use, sharing, adaptation, distribution and reproduction in any medium or format, as long as you give appropriate credit to the original author(s) and the source, provide a link to the Creative Commons licence, and indicate if changes were made. The images or other third party material in this article are included in the article's Creative Commons licence, unless indicated otherwise in a credit line to the material. If material is not included in the article's Creative Commons licence and your intended use is not permitted by statutory regulation or exceeds the permitted use, you will need to obtain permission directly from the copyright holder. To view a copy of this licence, visit http://creativecommons.org/licenses/by/4.0/ The Creative Commons Public Domain Dedication waiver (http://creativecommons.org/publicdomain/zero/1.0/) applies to the data made available in this article, unless otherwise stated in a credit line to the data. 
The aim of this study was to report about the safety and feasibility of flank hernias repair with a minimally invasive robotic-assisted approach.

\section{Methods}

\section{Patients' inclusion}

Written non-opposition consents were administered to patients and the local ethical committee approved the study (Comitato Etico Cantonale Ticino n. 2019-01132 CE 3495). STROBE statement was applied [15].

At the Bellinzona Regional Hospital, Switzerland, a retrospective search on a prospectively collected dataset on robotic surgery over a 2-years period, from January 2018 to December 2019, was performed. We included all patients who were treated for an incisional flank hernia with a robotic-assisted approach. Flank hernias were defined according to the definition of Muysoms FE et al. [1]: lateral to the rectal sheath in the area $3 \mathrm{~cm}$ above and below the umbilicus but not located in the lumbal, iliac or subcostal regions. Patients were excluded in case of flank bulges, defined as a protrusion of the abdominal content without any interruption or defect of the abdominal fascia.

The dataset included demographic and clinical records such as age and sex, past medical history, hernia etiology, symptoms, defect side and larger diameter, mesh dimension, operative times, conversion rate, length of hospital stay, complications and recurrence rate at 6 months (Table 1). All operations were performed by the same two senior general surgeons. All patients were followed-up in our outpatient clinic at 1 and 6 months after surgery, were asked about chronic pain and underwent a clinical examination to rule out the presence of seroma or recurrence.

Descriptive statistics were presented as absolute frequencies and percentage for categorical variables and median with interquartile ranges (IQR) for continuous variables.

\section{Operative technique}

The operations were performed in the supine position under general anesthesia with preoperative antibiotic therapy and antithrombotic devices. The pneumoperitoneum was created either inserting a Verres needle in the left subcostal region or with the open technique according to the past surgical history and surgeon's preference. Three 8-mm robotic trocars were inserted along the pararectal line, opposite to the hernia site. One $5 \mathrm{~mm}$ assistant trocar was inserted between and lateral to two of the robotic trocars (Fig. 1). After the docking of the Da Vinci Xi robot system (Intuitive Surgical) we used tree robotic arms, firstly inserting the $30^{\circ}$ camera through arm 2, then the fenestrated bipolar forceps through arm 1 and the monopolar curved scissors through arm 3.

After careful dissection of the peritoneal adhesions, it is essential to incise the peritoneum at least $5 \mathrm{~cm}$ medially to the medial hernia margin, in order to create the preperitoneal space for a proper mesh overlap. To achieve this, a sterile measuring tape was used to measure the peritoneum incision line. The preperitoneal space was completely prepared and the hernia sack dissected from the subcutaneous tissue. The fine robotic assisted preperitoneal dissection can be performed taking care not to injure the peritoneum, also where it is typically very thin, i.e. posterior to rectus sheaths. After complete preparation of the preperitoneal space to guarantee a $5-\mathrm{cm}$ mesh overlap on the hernia defect (Fig. 2), we inserted a suction Redon drain through the skin in order to prevent a postoperative seroma. Generally, the drain was left in place for $48 \mathrm{~h}$ after surgery.

After inserting the robotic needle holder through the arm 3, the hernia defect was closed with a continuous Covidien V-Loc-0 barbed suture, usually under a pneumoperitoneum pressure of $8 \mathrm{mmHg}$. Once closed the hernia defect, we used again the sterile measuring tape to exactly cut the mesh (Covidien Parietene) to the measured size and shape. The mesh fixation was achieved with several interrupted Vicryl 3-0 sutures. At the end, the peritoneum was sutured with a continuous Covidien V-Loc 4-0 barbed suture. After the robot undocking, the trocars were removed under vision and the fascia was not closed (Video 1).

\section{Results}

From January 2018 to December 2019, out of 190 patients who underwent robotic-assisted hernia surgery, 39 were treated for an incisional hernia, of whom seven consecutive patients with a flank hernia were included in the present study. Median age was 69.0 years (IQR 63.2$78.0)$, two patients were male $(29 \%)$ and body mass index (BMI) was $27.3 \mathrm{~kg} / \mathrm{m}^{2}$ (IQR 25.8-32.3). Three patients had hypertension (43\%), one cardiac history (14\%), two diabetes (29\%) and one obesity (14\%). All patients were referred to surgery because of pain, whereas one of them described recurrent episodes of small bowel obstruction. All hernias were incisional, three after a flank laparotomy and four trocar site hernias.

The median measure of the hernia defect was $25 \mathrm{~mm}$ (IQR 21-40), the median mesh larger diameter was 10 $\mathrm{cm}$ (IQR 10-12.5) and the median operative time was 137 min (IQR 133-174). No intraoperative complication occurred and no cases of conversion to open surgery were recorded.

Postoperatively, one patient affected from chronic obstructive pulmonary disease developed a pneumonia, which led to a longer hospital stay and was successfully treated with antibiotic therapy. The median length of hospital stay was 4.0 days (IQR 3.0-7.7). At 6 months after surgery all patients completed the follow-up and neither seroma/recurrence nor chronic pain were recorded. 


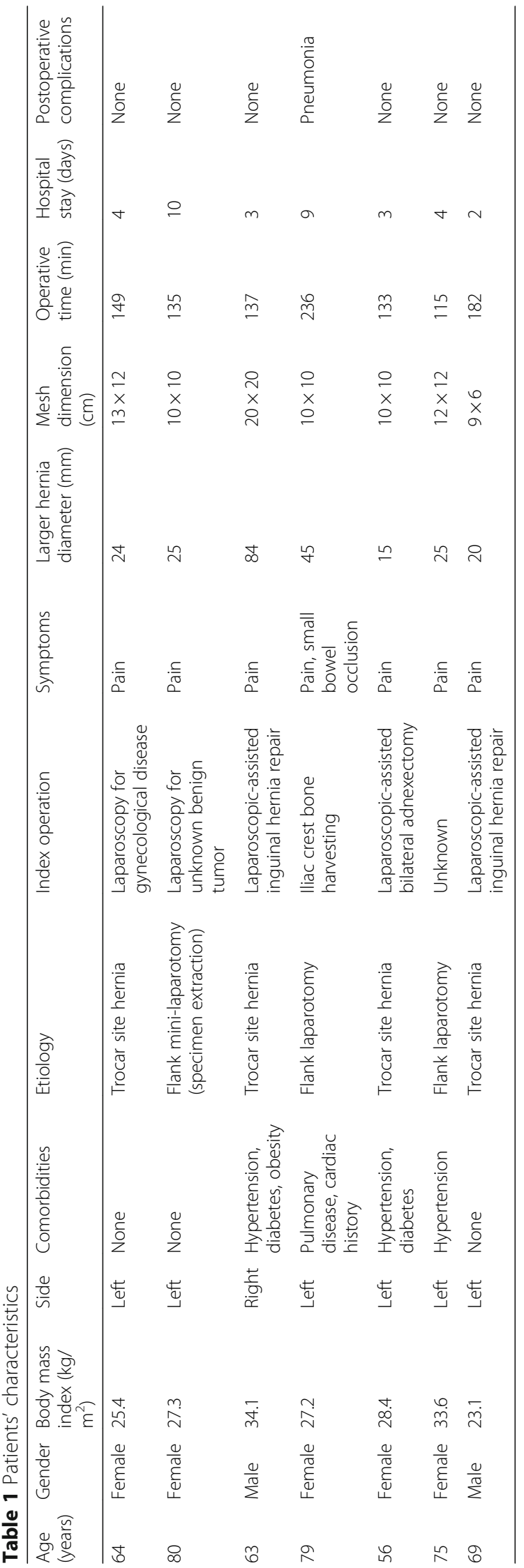




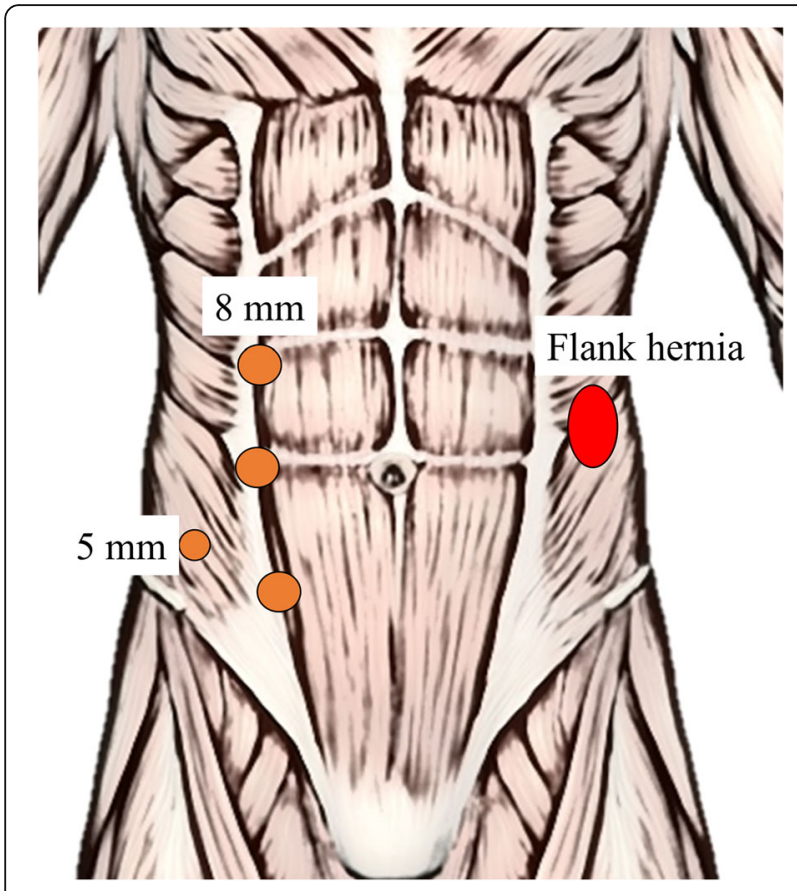

Fig. 1 Trocar placement on the abdomen

\section{Discussion}

Our study shows high successful rate of the robotic approach in flank hernia surgery, without any case of conversion to open surgery or presence of recurrence during a 6-month follow-up.

Hernias of the flank are an uncommon occurrence in everyday surgical practice. According to the European Hernia Society, in flank hernias the fascial defect is localized lateral to the rectal sheath in the area $3 \mathrm{~cm}$ above and below the umbilicus [1]. Such classification clearly distinguishes these hernias from the iliac and subcostal ones, as well as from flank bulges. The latter, in fact, occurs in absence of an obvious fascial defect and should not be understood as a hernia, but as a denervation injury of the musculoaponeurotic layers of the flank [6]. Almost all flank hernias occur after a surgical operation either laparoscopic or open, even if other causes are occasionally reported [2-4]. After a flank incision, hernias can occur in up to $17 \%$ of patients. Known risk factors are the incision length, the presence of metabolic syndrome, smoke, heart, lung and renal diseases [5].

The indication to surgically treat a flank hernia is clear in symptomatic cases, as an intermediate risk of complications, such as incarceration and strangulation, has been reported [7]. The treatment strategy depends on several factors but, anyhow, it comes down to challenging operations. In fact, the regional bone and neurovascular structures limit the safety and feasibility of mesh fixation and overlap [2]. In addition, due to the rarity of such surgical condition, no standardized technique can be suggested. Several approaches have been described in the literature and, in the minimally invasive era, the laparoscopic repair with mesh placement whether intraperitoneal or preperitoneal seems to represent a valid treatment option [2, 9, 10, 16-21].

In our previous experience of laparoscopic flank hernia repair, we encountered technical difficulties during the dissection of the preperitoneal space, as the thin peritoneal layer may break or even the posterior rectus sheath can be injured. In addition, a closure of the fascial defect is rarely achievable with laparoscopy. Since 2017, in our Department of General Surgery, the treatment of abdominal wall hernias is performed with a roboticassisted minimally invasive approach, using the da Vinci Xi system (Intuitive Surgical). The da Vinci system offers a $30^{\circ}$ - 3D camera with magnificent visualization of the operative field. Its technology provides for high precision movements. Thanks to the EndoWrist technologyrelated instruments' range of motion, the da Vinci

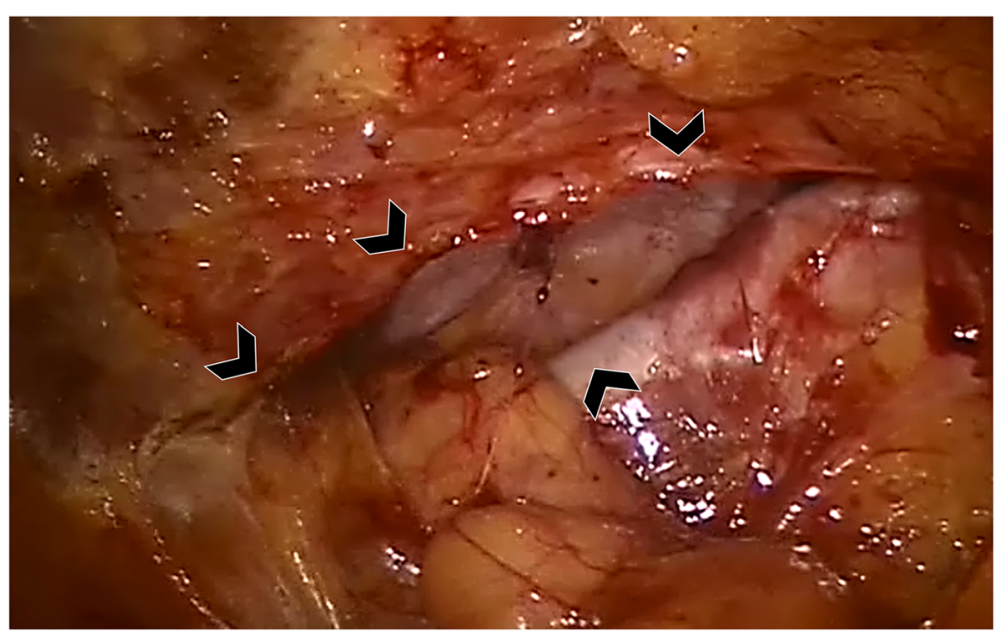

Fig. 2 Intraoperative image showing the hernia defect and the prepared preperitoneal space 
system allows precise dissecting and suturing in narrow spaces, in our opinion hardly achievable with other minimally invasive techniques. Therefore, according to our experience, in minimally invasive hernia surgery, preperitoneal dissection, components separation, fascial defect closure and mesh fixation are properly to perform and, in complex cases, better achievable with robot-assisted surgery [22].

From January 2018 to July 2019, we performed 7 consecutive robot-assisted preperitoneal repair of flank hernias. None of the operations had to be converted to open surgery. We systematically treated patients with hernia defect closure and $5 \mathrm{~cm}$ mesh overlapping in order to minimize seroma, bulging and recurrence, following the recommendations of the International Endo Hernia Society (IEHS) [23]. Furthermore, we decided to include only patients with incisional hernias, as treatment and outcomes in case of congenital defect may vary and represent a source of bias [24].

In a series of 22 patients affected from lateral abdominal wall hernias and treated with open surgery, Cavalli $M$ et al. [8] reported an early complication rate of $9.1 \%$ (two cases of hematoma), a mean length of hospital stay of 4.8 days and one case of recurrence after a mean follow-up of 44 months. In the literature dealing with open treatment of flank hernias, the reported complication rate varies from 3 to $42 \%$ and the recurrence rate from 0 to $11 \%$ [2, 3, 9-11]. Edwards C et al. [7] reported on 27 patients with flank hernias operated laparoscopically. The length of hospital stay was 3.1 days. No recurrence was seen after 4 months follow-up. However, 3 patients had chronic postoperative pain, presumably secondary to mesh fixation or compression of nerve structures. Novitsky YW et al. [25] described excellent results of laparoscopic treatment of flank hernias in 14 patients with short hospital stays and no recurrence after 35 months. However, all hernias were of traumatic origin. Interestingly, the authors themselves commented how robot-assisted surgery may facilitate the minimally-invasive repair of flank hernias and extend the minimal access benefits to hernias that are commonly treated with open surgery.

In our series, no conversion to open surgery was necessary. Median length of hospital stay was 4 days and one patient with medical history of severe chronic obstructive pulmonary disease developed a postoperative pneumonia that required a longer hospital stay, physiotherapy and antibiotic therapy.

This study has several limitations. Its nature does not include a comparison group and, due to its retrospective design, the data were not measured in a standardized way, with inherent measurement bias. In addition, a small number of cases was included, as flank hernias represent an uncommon surgical occurrence. For those cases, we have no data about a long-term follow-up.
Furthermore, the use of robots in general surgery remains controversial, also when the general surgical community appears to show a growing interest in robotassisted procedures despite lack of evidence and increase of costs [22]. Before our robotic experience, we observed in the laparoscopic treatment of this kind of hernia a significant rate of conversion to open surgery because of several reasons: difficulties in the creation of the preperitoneal space with multiple peritoneal defects, unachievable fascial closure, impossible or too risky mesh fixation due to regional bone and neurovascular structures. In all patients we converted to open surgery, the hospital stay was significantly longer and, as a result of this, the inhospital costs were consistently higher. In our series, none of the seven operations had to be converted to open surgery. Consequently, five on seven patients had short hospital stays. In this sense, we feel that a reduced length of stay may offset the costs of robotic surgery. However, in the current literature, there are only a few data, and none dealing with abdominal hernias, supporting our assertion $[26,27]$.

\section{Conclusions}

Robotics in abdominal wall hernia surgery remains a matter of debate, despite a growing interest from the surgical community. In our reported experience with flank hernias, we found the robotic-assisted approach to be safe and feasible for the treatment of this uncommon clinical entity. Larger studies are needed to confirm our initial experience.

\section{Supplementary information}

Supplementary information accompanies this paper at https://doi.org/10. 1186/s12893-020-00843-3.

Additional file 1: Video 1. Flank hernia repair with a robotic-assisted approach.

Abbreviations

IQR: Interquartile ranges; BMI: Body mass index.

\section{Acknowledgements}

None.

\section{Authors' contributions}

Protocol/project development: MDG, RP. Data acquisition and interpretation: MM, DLR. Statistical analysis: FM. Manuscript drafting. MDG, DLR, RP. Manuscript revision and accountable for all aspects of the work: FM, MM. All authors approved the final version of the manuscript.

\section{Funding}

The authors report no grant or financial support.

\section{Availability of data and materials}

The datasets used and/or analysed during the current study are available from the corresponding author on reasonable request. 


\section{Ethics approval and consent to participate}

Written non-opposition consents were administered to patients and the local ethical committee approved the study (Comitato Etico Cantonale Ticino n. 2019-01132 CE 3495).

\section{Consent for publication}

Written non-opposition consents were obtained from all patients for publication.

\section{Competing interests}

The authors declare that they have no competing interests.

\section{Author details}

'Department of Surgery, Ospedale Regionale di Bellinzona e Valli, via Ospedale 12, 6500 Bellinzona, Switzerland. ${ }^{2}$ Department of Surgery, Ospedale Regionale di Lugano, via Tesserete 46, 6900 Lugano, Switzerland.

Received: 9 April 2020 Accepted: 5 August 2020

Published online: 12 August 2020

\section{References}

1. Muysoms FE, Miserez M, Berrevoet F, Campanelli G, Champault GG, Chelala $\mathrm{E}$, et al. Classification of primary and incisional abdominal wall hernias. Hernia. 2009:13(4):407-14.

2. Phillips MS, Krpata DM, Blatnik JA, Rosen MJ. Retromuscular preperitoneal repair of flank hernias. J Gastrointest Surg. 2012;16(8):1548-53.

3. Bender JS, Dennis RW, Albrecht RM. Traumatic flank hernias: acute and chronic management. Am J Surg. 2008;195(3):414-7.

4. Montes-Tapia F, Cura-Esquivel I, Gutiérrez S, Rodríquez-Balderrama I, de la OCavazos M. Congenital lateral abdominal wall hernia. Pediatr Int. 2016;58(8): 788-90

5. Zhou DJ, Carlson MA. Incidence, etiology, management, and outcomes of flank hernia: review of published data. Hernia. 2018;22(2):353-61.

6. Gardner GP, Josephs LG, Rosca M, Rich J, Woodson J, Menzoian JO. The retroperitoneal incision. An evaluation of postoperative flank 'bulge'. Arch Surg. 1994;129(7):753-6.

7. Edwards C, Geiger T, Bartow K, Ramaswamy A, Fearing N, Thaler K, et al. Laparoscopic transperitoneal repair of flank hernias: a retrospective review of 27 patients. Surg Endosc. 2009;23(12):2692-6.

8. Cavalli M, Aiolfi A, Morlacchi A, Bruni PG, Del Ferraro S, Manfredini L, et al. An extraperitoneal approach for complex flank, iliac, and lumbar hernia. Hernia. 2020. https://doi.org/10.1007/s10029-020-02214-6.

9. Patel PP, Warren JA, Mansour R, Cobb WS 4th, Carbonell AM. A large singlecenter experience of open lateral Abdominal Wall hernia repairs. Am Surg. 2016;82(7):608-12.

10. Veyrie N, Poghosyan T, Corigliano N, Canard G, Servajean S, Bouillot J Lateral incisional hernia repair by the retromuscular approach with polyester standard mesh: topographic considerations and long-term follow-up of 61 consecutive patients. World J Surg. 2013;37(3):538-44

11. Fei Y, Li L. Comparison of two repairing procedures for abdominal wall reconstruction in patients with flank hernia. Zhongguo Xiu Fu Chong Jian Wai Ke Za Zhi. 2010;24(12):1506-9.

12. Nikolian VC, Coleman NL, Podolsky D, Novitsky YW. Robotic-assisted Transabdominal Preperitoneal ventral hernia repair. Surg Technol Int. 2020 36:95-7.

13. Orthopoulos G, Kudsi OY. Feasibility of robotic-assisted Transabdominal Preperitoneal ventral hernia repair. J Laparoendosc Adv Surg Tech A. 2018; 28(4):434-8.

14. Earle D. Robotic-assisted laparoscopic ventral hernia repair. Surg Clin North Am. 2020;100(2):379-408.

15. Von Elm E, Altman DG, Egger M, Pocock SJ, Gøtzsche PC, Vandenbroucke JP. STROBE initiative. The strengthening the reporting of observationa studies in epidemiology (STROBE) statement: guidelines for reporting observational studies. Lancet. 2007:370(9596):1453-7.

16. Hope WW, Hooks WB 3rd. Atypical hernias: suprapubic, subxiphoid, and flank. Surg Clin North Am. 2013;93(5):1135-62

17. Luc G, David A, Couzi L, Midy D, Collet D, Dubuisson V. Lateral incisional hernia after renal transplantation: a comparative study. World J Surg. 2014; 38(11):2791-6
18. Pezeshk RA, Pulikkottil BJ, Bailey SH, Schaffer NE, Reece EM, Thornton NJ, et al. An evidence-based model for the successful treatment of flank and lateral Abdominal Wall hernias. Plast Reconstr Surg. 2015;136(2):377-85.

19. Purnell CA, Park E, Turin SY, Dumanian GA. Postoperative flank defects, hernias, and bulges: a reliable method for repair. Plast Reconstr Surg. 2016; 137(3):994-1001

20. Varela JE, Kane K. Laparoscopic repair of large flank hernia staged with laparoscopic sleeve gastrectomy in the morbidly obese. Surg Obes Relat Dis. 2009:5(4):513-6. https://doi.org/10.1016/.j.soard.2008.12.004.

21. Beffa LR, Margiotta AL, Carbonell AM. Flank and lumbar hernia repair. Surg Clin North Am. 2018:98(3):593-605.

22. Donkor C, Gonzalez A, Gallas MR, Helbig M, Weinstein C, Rodriguez J. Current perspectives in robotic hernia repair. Robot Surg. 2017:4:57-67.

23. Bittner R, Bingener-Casey J, Dietz U, Fabian M, Ferzli GS, Fortelny RH, Köckerling F, et al. Guidelines for laparoscopic treatment of ventral and incisional abdominal wall hernias (international Endohernia society (IEHS)part 1. Surg Endosc. 2014;28(1):2-29.

24. Stabilini C, Cavallaro G, Dolce P, Capoccia Giovannini S, Corcione F, Frascio $\mathrm{M}$, Sodo $\mathrm{M}$, et al. Pooled data analysis of primary ventral (PVH) and incisional hernia $(\mathrm{IH})$ repair is no more acceptable: results of a systematic review and metanalysis of current literature. Hernia. 2019;23(5):831-45.

25. Novitsky YW. Laparoscopic repair of traumatic flank hernias. Hernia. 2018; 22(2):363-9

26. Jayne D, Pigazzi A, Marshall H, Croft J, Corrigan N, Copeland J, et al. Effect of robotic-assisted vs conventional laparoscopic surgery on risk of conversion to open laparotomy among patients undergoing resection for rectal Cancer: the ROLARR randomized clinical trial. JAMA. 2017;318(16):1569-80.

27. Jeong IG, Khandwala YS, Kim JH, Han DH, Li S, Wang Y, et al. Association of Robotic-Assisted vs laparoscopic radical nephrectomy with perioperative outcomes and health care costs, 2003 to 2015. JAMA. 2017;318(16):1561-8.

\section{Publisher's Note}

Springer Nature remains neutral with regard to jurisdictional claims in published maps and institutional affiliations.

Ready to submit your research? Choose BMC and benefit from:

- fast, convenient online submission

- thorough peer review by experienced researchers in your field

- rapid publication on acceptance

- support for research data, including large and complex data types

- gold Open Access which fosters wider collaboration and increased citations

- maximum visibility for your research: over $100 \mathrm{M}$ website views per year

At BMC, research is always in progress.

Learn more biomedcentral.com/submissions 